\title{
田
}

\section{NOTAS SOBRE A ORGANIZACCÃO POLÍTICO-SINDICAL DOS ASSISTENTES SOCIAIS NA ATUALIDADE}

\author{
NOTES ON POLITICAL AND TRADE UNION ORGANIZATION OF SOCIAL \\ WORKERS IN THE NEWS
}

\section{Renata de Oliveira Cardoso}

\section{RESUMO}

O presente artigo pretende analisar a organização político-sindical dos assistentes sociais do Brasil na atualidade, a partir do estudo crítico da Federação Nacional dos Assistentes Sociais (FENAS), criada nos anos 2000. Para efetuar tal discussão, retoma-se neste estudo, as diretrizes do movimento chamado novo sindicalismo, e seus impactos para o Serviço Social durante a década de 1980 que, dentre outros, se expressou na deliberação e tentativa de transição dos assistentes sociais de seus sindicatos corporativos para os constituídos por ramo de atividade econômica. Infelizmente, esta transição foi inconclusa não só por questões próprias à categoria, mas sobretudo pela consolidação da plataforma neoliberal e pela crise do sindicalismo nacional, na década de 1990. Nesse sentido, nos parece importante reafirmar que os sindicatos - desde que tenham liberdade, autonomia sindical e direção política comprometida com a emancipação humana - são instrumentos interessantes à organização dos trabalhadores e à luta contra o capital. Por isso, a análise crítica da Federação pode contribuir para o debate sobre a reorganização político-sindical dos assistentes sociais na atualidade.

\footnotetext{
1 Professora do curso de Serviço Social na Universidade Federal Fluminense de Rio das Ostras desde janeiro de 2013. Doutoranda em Serviço Social no Programa de Pós Graduação da Universidade Federal do Rio de Janeiro (UFRJ). Mestre em Serviço Social pela UFRJ (2012) e bacharel em Serviço Social pela mesma universidade (2008). Formação com ênfase nas seguintes temáticas: políticas públicas, reformas do estado, organização dos trabalhadores, formação profissional e Serviço Social.
} 


\section{temporollis}

Palavras-chave: Serviço Social. Organização Político-Sindical. Novo Sindicalismo. Transição Inconclusa.

\section{ABSTRACT}

This article aims to analyze the political and trade union organization of social workers in Brazil today, from the critical study of the National Federation of Social Workers (FENAS), created in the 2000s. To make such discussion is taken up in this study, movement of guidelines called new unionism, and its impact on the social service during the 80 that, among others, expressed in the resolution and attempt the transition from social workers to their corporate unions for constituted by branch of economic activity. Unfortunately, this transition was inconclusive not only own questions to the category, but above all the consolidation of neoliberal platform and the national syndicalism crisis in the gos this sense, it seems important to reaffirm that the unions - provided they have freedom, autonomy union and political leadership committed to human emancipation - are interesting instruments to the organization of workers and the fight against capital. Therefore, the critical analysis of the Federation can contribute to the debate on the political and trade union reorganization of social workers today.

Keywords: Social Service. Political and Trade Union Organization. New Unionism. Unfinished Transition.

Submissão - 11/09/2016

Aceite $-13 / 01 / 2017$

\section{Introdução}

Para analisarmos a organização político-sindical dos assistentes sociais na atualidade, precisamos nos reportar à trajetória sócio-histórica mais recente do sindicalismo da categoria, considerando os processos da luta de classes que influenciaram o devir e a composição sindical do Serviço Social no Brasil.

No percurso realizado para atender ao objetivo proposto, foi possível perceber que, durante a década de 1970, o Brasil se viu afundado em uma grande crise econômica e os trabalhadores logo mostraram seu descontentamento. Passamos por um período de enorme crescimento dos movimentos sociais, que reivindicavam, entre outras coisas, o fim da ditadura e a redemocratização do País.

A esse contexto seguiu-se um período de "abertura política" que propiciou a criação de novas entidades de organização da classe 


\section{tempordis}

trabalhadora sob a égide do chamado "novo sindicalismo". O novo sindicalismo foi uma forma de conceber a organização dos trabalhadores que revelou as necessidades de uma estrutura sindical de caráter autônomo para enfrentar o capital. Duas das maiores expressões deste processo foram a Central Única dos Trabalhadores (CUT) e o Partido dos Trabalhadores (PT), ambos criados durante a década de 1980.

A organização político-sindical dos assistentes sociais, vinculada aos interesses gerais da classe trabalhadora, não ocorreu de forma deslocada do novo sindicalismo - que contribuiu de forma decisiva para a transformação da dinâmica política brasileira e para a elaboração da Constituição Federal de 1988, considerada marco histórico de garantia de direitos aos trabalhadores.

No começo da década de 1990, todavia, a política econômica no Brasil baseou-se e foi incentivada pela mundialização do capital e pela política neoliberal que incidiram diretamente nas expressões e representações do movimento sindical. As novas maneiras de organização do processo de trabalho e de gestão da força de trabalho alteraram o perfil dos trabalhadores e contribuiu para a fragmentação da organização dos trabalhadores.

Por isso, o final da década de 1990 assistiu ao início do refluxo dos movimentos sociais e dos instrumentos de organização da classe trabalhadora, instaurando-se a chamada crise do sindicalismo. Se durante o novo sindicalismo, existiram propostas de ruptura da relação entre sindicato e estado, entre os anos 1990 e 2000, algumas entidades passam a compactuar com os interesses capitalistas - o que contribuiu, de forma significativa, para a desarticulação da classe trabalhadora e para a não implementação da estrutura combativa proposta pelo novo sindicalismo às suas entidades.

Foi nesse contexto de crise do sindicalismo que surgiu a Federação Nacional dos Assistentes Sociais (FENAS), cuja plataforma, desde a origem até os dias atuais nos coloca o desafio de enfrentar $\mathrm{o}$ sindicalismo falido em âmbito nacional.

\section{Organização sindical e Serviço Social}

A trajetória da organização político-sindical dos assistentes so- 


\section{temporalis}

ciais data da década de 1950, com associações de caráter pré-sindical, as chamadas Associações Profissionais de Assistentes Sociais (APAS) e os primeiros sindicatos, do início da década seguinte. Porém, não existia uma entidade sindical de caráter nacional. A década de 1970 foi o período de rearticulação das entidades da categoria, visto que, durante a ditadura militar, muitas delas haviam sido fechadas. Foi a partir desta necessidade que se fundou a Comissão Executiva Nacional de Entidades Sindicais de Assistentes Sociais (CENEAS), que, no período de 1978 a 1983, concentrava a organização nacional dos assistentes sociais. (ABRAMIDES; CABRAL, 1995).

Antes da criação da CENEAS, alguns Encontros Nacionais de Entidades Sindicais aconteceram e, de maneira não isolada, tais encontros pensavam a reorganização da categoria sob a ótica do novo sindicalismo, inserida na conjuntura de efervescência política e ascensão das lutas dos trabalhadores. Os três encontros que antecederam a criação da Comissão tinham como eixos políticos e reivindicatórios questões orientadas às condições de trabalho e salário, além da necessidade de reorganização dos assistentes sociais.

Diante da realidade de luta emergente no período de redemocratização do País, tornou-se urgente a criação de mecanismos de unificação de entidades pré-sindicais e sindicais que fossem consequentes com as pautas nacionais deliberadas nos espaços da categoria. Assim, em setembro de 1979, houve o III Encontro Nacional das Entidades Sindicais de Assistentes Sociais, que tinha por objetivo realizar uma articulação política das entidades sindicais para o III Congresso Brasileiro de Assistentes Sociais (CBAS), também chamado de "Congresso da Virada" (PAULO NETTO, 2009), ocorrido dias depois do encontro. O III CBAS foi realizado em um período de grande efervescência no País e refletiu, também, o momento que o Serviço Social vivenciava no Brasil e na América Latina - o processo de crítica ao tradicional, a chamada "Renovação".

Nesse período, na categoria profissional, o setor conservador concentrava-se no Conselho Federal de Assistentes Sociais (CFAS) e dos Regionais (CRAS) ${ }^{2}$, que se encontravam sob a orientação política e ideológica das correntes conservadoras. Nesse sentido, pode-se depreender que o III Congresso foi organizado e idealizado, no tocante à

2 Nos dias atuais, as siglas CFAS e CRAS foram substituídas pelo Conselho Federal de Serviço Social (CFESS) e pelo Conselho Regional de Serviço Social (CRESS). 


\section{tempordis}

sua estrutura, funcionamento e pautas de discussão, por uma política de continuidade conservadora.

Por isso, o III Encontro Nacional de Entidades Sindicais, que antecedeu o III CBAS, teve como resultado a elaboração de um documento crítico ao congresso. (ABRAMIDES; CABRAL, 2009a). Assim, a grande virada se expressou durante o congresso e teve seu principal pilar no compromisso assumido pela categoria com o conjunto de interesses dos movimentos populares e sindicais. As deliberações das assembleias, que aconteciam diariamente no evento, impuseram à comissão organizadora a alteração da programação do evento.

Durante o congresso, a categoria conseguiu se contrapor à vertente conservadora no seu interior, que tivera longos anos de prática em consonância com a política das correntes que propunham, no Brasil, a submissão incondicional daqueles que produzem a riqueza. Todavia, a ruptura foi possível, entre outros aspectos, por meio da realocação dos profissionais em face da sua organização político-sindical. (ABRAMIDES; CABRAL, 2009a).

A categoria, que foi organizada politicamente para o congresso sob a direção da CENEAS, deliberou, durante o III CBAS, um projeto profissional comprometido com a classe trabalhadora e decidiu, ainda, que a coordenação dos próximos congressos aconteceria por intermédio da CENEAS, reconhecendo sua capacidade de organização político-sindical.

O IV CBAS, que ocorreu em 1982 e sucedeu ao Congresso da Virada, também foi bastante categórico naquilo que diz respeito à organização sindical dos assistentes sociais. Das suas deliberações, destacamos: a necessidade de transformação das APAS em sindicatos; de avançar na construção de uma nova entidade nacional; e, ainda, do empenho na construção de uma CUT que fosse democrática e independente.

Assim, durante o IV CBAS, deliberou-se a realização da I Assembleia Nacional Sindical dos Assistentes Sociais, que ocorreu em outubro de 1982 e passou a ser o fórum máximo de deliberação sindical da categoria. Durante o evento, foi fundada a Associação Nacional dos Assistentes Sociais (ANAS), que funcionou como entidade político-sindical pró-federação, em âmbito nacional, durante os primeiros anos da década de 1980, até 1986, quando se constituiu, definitivamente, 


\section{temporalis}

como uma federação ${ }^{3}$. Após o IV CBAS, os assistentes sociais reafirmaram seu compromisso com o conjunto da classe trabalhadora.

Como vimos, a organização político-sindical dos assistentes sociais no Brasil esteve intimamente relacionada com as transformações societárias oriundas do processo de "abertura política", de acirramento da luta de classes, com o ascenso dos movimentos sociais e o protagonismo do operariado. Apesar disso, as orientações e deliberações do sindicalismo cutista foram significativas para as transformações referentes à organização sindical do Serviço Social.

\section{Novo sindicalismo e a organização político-sindical dos assistentes sociais}

A CUT, durante seus anos de enfrentamento com o governo ditatorial, teve forte influência na reorganização do movimento sindical no Brasil, orientando e definindo pilares para a luta de classes no plano nacional. Seus Congressos expressavam não somente análises que diziam respeito à conjuntura nacional, mas também revelavam direções a serem seguidas pelo conjunto dos trabalhadores.

Durante a década de 1980, a CUT denunciava a profunda e prolongada crise econômica vivida no Brasil. Apesar dos índices de crescimento e desenvolvimento das forças produtivas, as melhorias na qualidade de vida dos trabalhadores não eram garantidas, pois o arrocho salarial permanecia; a fome e a desnutrição afetavam grande parte da população; a enorme concentração de propriedades de terras no campo contribuía para o desemprego; e o processo de contrarreforma do Estado iniciava a privatização dos serviços públicos.

Ao analisarmos o documento do $2^{\circ}$ Concut, é palmar que a Central se colocava contrária à conjuntura de exploração imposta aos trabalhadores e que defendia os interesses históricos e imediatos da classe, rumo à democracia e ao socialismo. A construção de um projeto alternativo de sociedade era reafirmada, porém, com independência e liberdade com relação ao estado e aos partidos políticos.

A CUT, enquanto central sindical, [...] faz avançar a luta

3 Cabe ressaltar que as Assembleias Sindicais da ANAS eram bianuais e existiram até 1994 . 


\section{tempordils}

de classes quando consegue impulsionar as lutas sindicais, articular as lutas econômicas com os objetivos políticos, organizar e elevar o nível de consciência de classe, apontar para a construção de uma sociedade socialista, mas não deve ser confundida com um partido político e manterá sempre sua autonomia em relação ao poder de estado e aos próprios partidos. (CUT, 1986, p. 3, grifo do autor)

Nesse contexto, a principal tarefa dos sindicatos era a de unificar a ação sindical que deveria ser cotidiana, contemplando trabalhadores do campo e da cidade, dos setores privado e público. Implantar a nova estrutura sindical era tarefa do conjunto das organizações dos trabalhadores, um desafio no interior do sindicalismo classista que rompe com o corporativismo e tem como pilares: autonomia e liberdade sindical; corte classista; autossustentação financeira e democracia interna. Esses princípios foram consolidados no processo de luta e construção do novo sindicalismo no Brasil e, para alcançá-los, era necessária uma nova conformação sindical, que se traduziu na construção de sindicatos por ramo de atividade econômica. Caberia aos trabalhadores, tanto do setor público quanto do privado, formarem essa estrutura, desde os seus locais de trabalho até as instâncias superiores de organização.

No que concerne ao serviço social, que tinha grande parte da vanguarda ativista inserida no PT e na CUT (ABRAMIDES; CABRAL, 1995), essas orientações foram trazidas para os espaços de discussão da categoria e seus participantes se empenharam na construção da nova estrutura sindical.

Apesar disso, a categoria esforçava-se para seguir na reorganização sindical dos assistentes sociais em todo o território nacional, conforme deliberação do IV CBAS. Das suas Assembleias Nacionais participavam tanto os sindicatos quanto as entidades pré-sindicais (APAS). O entendimento majoritário dos ativistas reafirmava a urgência de espaços que defendessem os interesses específicos dos assistentes sociais, como condições de trabalho e salário. Todavia, era necessário também articularem-se às lutas do conjunto da classe trabalhadora, oriundas, entre outros aspectos, da conjuntura política nacional e internacional.

A CENEAS, fundada em 1979, foi concebida como um mecanismo de articulação sindical e não pretendia, naquele momento, 


\section{temporolis}

construir uma federação. Isso porque a grande maioria das entidades político-organizativas dos assistentes sociais era representada pelas APAS e a legislação permitia somente às entidades sindicais formais vincularem-se às federações. Além disso, acreditava-se que a discussão acerca de uma federação para a categoria não estava amadurecida.

Em 1982, durante a I Assembleia Nacional Sindical dos Assistentes Sociais, algumas associações já haviam se transformado em sindicatos e essas instâncias coexistiam na luta, o que possibilitou a construção de uma entidade nacional. Assim, fundou-se a ANAS, também chamada de Associação Pró-federação, expressão do esforço por parte da CENEAS de construir uma entidade nacional.

Durante a década de 1980, as lutas específicas da categoria ganharam importância em todos os estados do País e tinham a expressividade e o protagonismo da CENEAS/ANAS. Contudo, não se diferenciavam das lutas mais gerais das demais categorias, pois tratavam de questões referentes ao trabalho, salário e outros.

Por isso, a articulação dos sindicatos e das associações da CENEAS/ANAS com o movimento mais geral dos trabalhadores favoreceu o desenvolvimento da consciência da categoria e contribuiu para a discussão da implementação da nova estrutura sindical proposta pela CUT - o que reafirmou o compromisso do Serviço Social com a emancipação da classe trabalhadora.

Um ano após o $2^{\circ}$ Concut, em 1987, na III Assembleia Sindical, a categoria definiu que a ANAS, a partir de então, seria a sua legítima federação - visto que fora construída no fórum coletivo, com ampla participação dos profissionais - e que nenhuma outra entidade seria reconhecida como tal. Houve algumas tentativas de oficialização da entidade; no entanto, elas foram rejeitadas pelo Ministério do TrabaIho, com a justificativa de que a ANAS era tão somente uma associação profissional e, dessa forma, não teria autoridade para requerer a carta sindical, somente os sindicatos a ela filiados. Em oposição, a categoria deliberou pelo reconhecimento da entidade como sua federação. (ABRAMIDES; CABRAL, 1995).

Nesse contexto, uma das principais tarefas políticas da ANAS era a construção da estrutura sindical proposta pela CUT, isto é, por ramo de atividade econômica. A decisão de construção dos sindicatos 
por ramo de atividade econômica foi reafirmada na IV Assembleia Sindical (1989), na qual a proposta foi deliberada por unanimidade. Além desse indicativo, a categoria aprovou a construção de uma entidade única no âmbito do Serviço Social, que responderia às questões específicas da categoria, como ação e inserção profissional. A proposta era a de que os assistentes sociais estariam inseridos nos diversos ramos das suas atividades, mas, ainda assim, teriam uma entidade própria para tratar de seus assuntos particulares.

Nos anos finais da década de 1980, a organização sindical dos assistentes sociais, expressou o giro da categoria para os sindicatos por ramo. Isto significou a extinção política da maioria dos sindicatos da categoria e da própria ANAS, em 1994, na sua $6{ }^{a}$ Assembleia. Este processo aconteceu de forma diferenciada em cada estado do País e a transição entre a velha estrutura sindical corporativa e a nova encontrou alguns impasses. De um lado, a difícil tarefa de articular os movimentos distintos, de criar novos sindicatos e findar os antigos; de outro, dever-se-ia convencer a categoria, em seu conjunto, deste projeto.

Apesar das indicações, quatro ${ }^{4}$ sindicatos permaneceram em funcionamento, desconsiderando a orientação. As decisões sindicais apontavam para o amadurecimento político da categoria e refletiam o novo contexto social. Todavia, o novo Projeto Profissional - atrelado ao projeto societário da classe trabalhadora - não era hegemônico entre os diversos espaços de discussão dos assistentes sociais, já que algumas de suas entidades representativas deliberaram, em seus sindicatos de base, orientações políticas diferenciadas. Isso nos leva a crer que existiam direções conservadoras, ainda que poucas, em algumas entidades sindicais da categoria.

No processo de transição, houve o esvaziamento das entidades por conta do giro da base para os sindicatos de ramo; em outros, as direções não fizeram o debate necessário com a categoria para efetivar o processo de transição; e existiram ainda aqueles que nem sequer consideraram a deliberação da IV Assembleia Sindical. Dessa forma, o trânsito foi inconcluso. Apesar dessa análise, a transitoriedade inconclusa (ABRAMIDES; CABRAL, 2009b) não pode ser estudada unicamente a partir do prisma do próprio Serviço Social. A profissão encontrou-se e encontra-se inserida no conjunto das relações socio-

4 Alagoas, Ceará, Rio Grande do Sul, Caxias do Sul (FENAS, 2010, p. 1). 


\section{temporollis}

econômicas, e cabe-nos tentar compreender quais foram os motivos dessa debilidade.

\section{0 projeto neoliberal e o movimento sindical cutista}

A década de 1990 no Brasil foi marcada pela implementação da política neoliberal e pela reestruturação produtiva - que significaram, para a classe trabalhadora, um conjunto de ataques aos direitos sociais, trabalhistas e políticos.

Essas transformações trouxeram impactos significativos à organização e atuação sindical da classe trabalhadora, pois, com a consagração eleitoral da plataforma neoliberal, a política brasileira retornou às linhas conservadoras, impondo ao movimento sindical a luta da defesa de direitos que, até então, pareciam consolidados.

A ofensiva neoliberal trazia consigo tantos ataques ao conjunto dos trabalhadores que as táticas defensivas direcionadas à manutenção dos direitos políticos, econômicos e sociais conquistados eram emergenciais. No entanto, não foi exatamente isso o que aconteceu. De forma processual, os espaços de organização dos trabalhadores, em especial os cutistas, passaram a defender posturas contrárias àquelas que carregavam consigo - de caráter classista e de oposição ao Estado.

Uma nova estratégia com relação à organização sindical vinha, no começo dos anos 1990, se conformando no interior da Central, que, agora, propagandeava serem necessários sindicatos "propositivos" diante da nova conjuntura política de consolidação do neoliberalismo e cantarolava o hino da modernidade ao som da necessária diminuição dos gastos sociais para, então, serem aumentadas a produtividade e a competitividade das empresas.

Já no $4^{\circ}$ Concut, realizado em setembro de 1991, a CUT redefiniu e consagrou quais seriam as prioridades de atuação dos sindicatos com relação à política do governo neoliberal. Dentre elas estava a ida ao chamado entendimento social. ${ }^{5}$

5 Tentativa de solucionar os impasses das relações de trabalho pela via da negociação. 


\section{tempordis}

A intenção, ao menos no discurso, era oferecer condições para que os sindicatos propusessem alternativas concretas aos problemas da política econômica no País, e não apenas se restringissem às reações defensivas. De certo modo, o argumento serviu de arcabouço para substituir a estratégia de ruptura com o corporativismo - que se apoiava na política de denúncia referente ao atrelamento dos sindicatos ao Estado e imprimia-Ihes um caráter classista - pelo de conciliação.

A partir da nova estratégia, a CUT passou a produzir propostas políticas setoriais, reivindicando, entre outros, a construção de fóruns tripartites formados por governo, associações patronais e sindicatos. Essa orientação começou a demarcar a ação sindical da base, alimentada, de certo modo, pela ilusão do caráter de conciliação de classes do Estado, desviando, dessa maneira, o que deveria ser o cerne das reivindicações: a luta contra o neoliberalismo.

O governo soube canalizar essa (re)localização da luta sindical e, por intermédio das suas contrarreformas, passou a incentivar a criação de conselhos ou fóruns compostos pela sociedade civil, pelo Estado e pelas instituições administradoras de serviço, que teriam a competência e a finalidade de avaliar as metas e a eficácia dos serviços públicos prestados.

Em paralelo a este movimento, os princípios e orientações firmados no $2^{\circ}$ Concut foram, paulatinamente, perdendo-se. 0 discurso de independência de classe e autonomia sindical - para nós, referencial de organização e resistência ao sistema capitalista - foi substituído pela tentativa sistemática de conciliação.

Naquilo que concerne à nova estrutura sindical proposta pela CUT na década de 1980, com a implementação do projeto neoliberal no Brasil, a Central reconheceu que pouco se avançou na concretização da deliberação referente à necessidade de organização dos trabaIhadores em sindicatos por ramo de atividade econômica e à ruptura com a estrutura sindical corporativa ultrapassada. Afirmou a Central: "Poucos avanços ocorreram no sentido de unificar as bases de sindicatos para tornar mais ampla a sua representação sindical [...]." (CUT, 1991, p. 6).

Percebemos, então, que o sindicalismo cutista começou a adotar posturas e discursos diferentes daqueles da década anterior, em 


\section{temporalis}

relação ao trato do enfrentamento da política neoliberal. Em paralelo a este processo, o movimento sindical como um todo sofreu profundas transformações que se expressaram em mudanças na sua forma de composição e atuação e, em particular, na sua capacidade de mobilização. Esse processo não é próprio do Brasil. A conjuntura política, já marcada pela reestruturação produtiva e pelas contrarreformas do Estado, seguiu com o enfraquecimento da organização dos trabalhadores e de suas entidades representativas.

O processo de flexibilização do trabalho e dos direitos dos trabalhadores contribuiu para a mudança de postura dos sindicatos, que passaram a dedicar sua atenção à "luta" pela conservação dos direitos conquistados anteriormente, e as negociações passaram a ser a sua principal expressão.

O sindicalismo nacional, de forma semelhante ao que se viveu nos países de capitalismo central na década de 1990, concentrou suas reivindicações na manutenção de direitos adquiridos anteriormente, e o projeto neoliberal não encontrou resistência concreta que se confrontasse com os seus ideais, pois o sindicalismo classista seguiu as estratégias sindicais neocorporativas ${ }^{6}$, de caráter propositivo, que abalaram a sua estrutura e fomentaram sua crise.

\section{A transição inconclusa e a organização político-sindical dos assis- tentes sociais na atualidade}

Os últimos anos da década de 1980 e os primeiros da década de 1990, naquilo que diz respeito à organização sindical dos assistentes sociais, expressaram o giro da categoria para os sindicatos por ramo, o que significou a extinção política da maioria dos sindicatos da categoria e da própria ANAS, em 1994. As deliberações do $2^{\circ}$ Concut foram decisivas para esta extinção, visto que a ANAS e os sindicatos a ela vinculados fomentaram a construção dos sindicatos por ramo de atividade econômica tal qual foi definido pela Central.

A partir das deliberações de ruptura com o sindicalismo corpo-

6 Compreendemos, neste estudo, as estruturas sindicais neocorporativas enquanto organizações de determinadas categorias ou mesmo de trabalhadores de uma determinada empresa que se fortalecem em detrimento da luta conjunta dos trabalhadores. 


\section{tempordils}

rativo, os assistentes sociais passaram a se inserir sindicalmente por área de contratação nos diversos ramos, bem como nos serviços públicos estaduais, municipais e federais. Em consonância, a extinção dos sindicatos da categoria se deu com o fortalecimento dos sindicatos gerais. Este processo aconteceu de forma diferenciada nos vários estados do País, e a transição da velha estrutura sindical corporativa para a nova esbarrou no conjunto de impasses imputado ao sindicalismo brasileiro desde as duas últimas décadas.

Ora, se o processo de transição dos sindicatos de assistentes sociais foi inconcluso, parte dos entraves esteve relacionado à consolidação da política neoliberal e à crise do sindicalismo no Brasil. Entre a deliberação do $2^{\circ}$ Concut e o fechamento dos sindicatos da categoria e da ANAS, o "sindicalismo combativo" deparou-se com as transformações do mundo do trabalho e com a nova postura adotada pela direção cutista, que seguiu o projeto de conciliação de classes, apelidado de "sindicalismo propositivo", levando ao corporativismo diversas categorias antes comprometidas com a luta unificada dos trabalhadores.

Como é possível observar, o processo de transição no Serviço Social foi afetado pelas transformações sindicais durante a ofensiva neoliberal. Apesar disso, outros elementos influenciaram tal transição, dentre eles a maneira pela qual se processou. De acordo com Abramides (2009), algumas entidades realizaram assembleias, seminários e diferentes espaços para orientar seus filiados a construírem os sindicatos por ramo de atividade; outras encerraram temporariamente suas atividades; e muitas, simplesmente, encontraram-se esvaziadas - dada a conjuntura deliberada de realocação nos sindicatos gerais, fazendo com que parte da categoria estivesse inserida nesses espaços.

Essa processualidade dificultada não se apresentou somente para a categoria dos assistentes sociais. No $7^{\circ}$ Concut, ocorrido em agosto de 2000, a CUT reafirmou os problemas referentes à campanha para a nova estrutura sindical que pouco havia avançado nos diferentes ramos e identificou questões em relação às suas finanças. Segundo a Central: "Uma avaliação criteriosa da campanha ainda está por ser feita, inclusive porque a sua continuidade é essencial para meIhorar o percentual de sindicalização e as condições financeiras de toda a CUT, suas instâncias e entidades filiadas." (CUT, 2000, p. 15). 


\section{temporollis}

Nos anais do $8^{\circ}$ Concut também encontramos reafirmações do que já era notório: a dificuldade na construção dos sindicatos por ramo de atividade, além de inseguranças referentes ao possível surgimento de outro projeto sindical. Apesar disso, os congressistas não apresentavam nenhuma alternativa em face da problemática da organização. Foi expressa, apenas, a necessidade de se manter o debate: "A CUT tem acúmulo suficiente para que esse processo ocorra com a implementação de salvaguardas que evitem brechas para que outros projetos sindicais se instalem em nossas bases." (CUT, 2002, p. 11).

O receio de outros projetos sindicais serem expressos estava relacionado às denúncias por parte das oposições internas, que relatavam o nefasto papel que a Central vinha cumprindo; a falta de democracia interna e a burocratização sindical. As oposições sindicais conformavam-se, as desfiliações cresciam, e iniciou-se, a partir de então, um processo de ruptura com a CUT em que diversos sindicatos deixaram de reconhecê-la como espaço para unificar e impulsionar as lutas dos trabalhadores brasileiros. Toda essa conjuntura leva-nos a acreditar que houve uma debilidade de debate e de proposições organizacionais em face dos impasses referentes à construção dos sindicatos por ramo, o que contribuiu para o fortalecimento dos sindicatos corporativistas em algumas categorias. No Serviço Social, essa análise do sindicalismo cutista, junto com aprofundamento da reestruturação produtiva, do neoliberalismo e da crise do sindicalismo, influenciou o surgimento de diversos sindicatos de assistentes sociais nas duas últimas décadas, bem como foi o pano de fundo para a reabertura dos que já existiam.

Sob o argumento de ter sido bastante lenta a sua organização político-sindical, foi criada, em 2000, a Federação Nacional de Assistentes Sociais (FENAS), cujos objetivos seriam os de aglutinar os sindicatos de assistentes sociais existentes e ser um espaço de discussão acerca da organização sindical da categoria, já que, nos Congressos de Serviço Social, haveria uma "falta de tolerância".

No IX CBAS-1998, em Goiânia, o debate referente à organização sindical mais uma vez não aconteceu... neste momento, por total omissão do CFESS para com os sindicatos, inclusive para anunciar a presença dos cinco sindicatos presentes na mesa de abertura, entendemos não ter espaço para dialogar com as entidades da categoria. (ALVARENGA; DALLARUVERA, 2007, p. 194). 
A FENAS foi criada durante a I Assembleia Sindical Pró-federação dos Assistentes Sociais (2000), com a presença de cinco ${ }^{7}$ sindicatos de assistentes sociais ${ }^{8}$ e, aproximadamente, 55 participantes - entre eles, profissionais, entidades políticas e representantes de instituições. ${ }^{9}$

Apesar de pouco representativo, o conjunto de sindicatos presentes durante a I Assembleia foi, contudo, suficiente para a criação da Federação, aprovada por unanimidade em 30 de novembro de 2000.

Os pressupostos para a criação da FENAS foram os mesmo para que, a partir de 2003, outros sindicatos de assistentes sociais fossem reativados, a maioria sob orientação da FENAS e apenas dois com reabertura independente, totalizando, em 2010, 12 sindicatos abertos. ${ }^{10}$

Vale ressaltar que as entidades representativas da categoria já em funcionamento, assim como a própria FENAS, se encontram no campo de atuação sindical da CUT:

[...] a CUT tanto reconhece nosso movimento que participamos dos congressos como delegados e fizemos e fazemos parte de diretorias da CUT Estadual, na executiva da CUT Nacional e atualmente na direção da CNTSS/ CUT. (FENAS, 2010, p. 3).

Diante desta conjuntura, algumas conclusões analíticas acerca da organização político-sindical dos assistentes sociais na atualidade podem ser consideradas.

7 Esse quantitativo mínimo de representações sindicais para a formação de uma federação é disposto no Artigo 534 da CLT

8 Alagoas, Ceará, Pelotas (RS), Porto Alegre (RS) e Rio de Janeiro.

9 Estiveram presentes a CUT, a Confederação Nacional dos Trabalhadores da Seguridade Social (CNTSS) e o Sindicato dos Auxiliares e Técnicos de Enfermagem do Rio de Janeiro. Além dessas, a I Assembleia contou com a participação de lideranças partidárias e do Conselho de Saúde do Rio de Janeiro. (ALVARENGA; DALLARUVERA, 2007).

10 De acordo com a FENAS (2013), os 12 sindicatos são: Ceará, Alagoas, Rio Grande do Sul, Caxias do Sul (RS), Rio de Janeiro, São Paulo, Pernambuco, Paraná, Pará, Mato Grosso, Maranhão e Amazonas, sendo estes dois últimos reabertos sem orientação da Federação. Os sete demais em processo de reabertura são: Bahia, Minas Gerais, Sergipe, Mato Grosso do Sul, Santa Catarina, Brasília, Rio Grande do Norte. 


\section{temporolis}

A primeira delas versa sobre a falta de legitimidade e espaços democráticos, por parte da FENAS para a construção e fomento do debate sobre a organização político-sindical dos assistentes sociais. Já a segunda, intimamente relacionada à primeira, trata das práticas burocráticas da Federação e a recusa a encampar a defesa das lutas dos assistentes sociais e demais trabalhadores. A terceira e última conclusão diz respeito à funcionalidade que os sindicatos dos assistentes sociais poderia ter para o projeto de fortalecimento da CUT em face aos impasses contemporâneos da Central.

Naquilo que diz respeito à falta de legitimidade e de espaços democráticos, diferentemente do que ocorreu com a ANAS, quando a categoria debateu sobre a criação desta entidade, apoiou suas lutas e a legitimou quando não foi reconhecida legalmente pelo Estado, a FENAS foi criada por processos questionáveis. Estiveram presentes na sua criação somente cinco sindicatos e um número pequeno de participantes que supostamente representavam, aproximadamente, 3.300 filiados em âmbito nacional. No entanto, os números não são suficientes para uma análise que gire em torno de sua possível legitimidade, tendo em vista que os métodos políticos para sua criação foram superficiais e pouco democráticos.

A FENAS afirma que houve um convite às entidades representativas da categoria e, em entrevista (HORTA, 2009), destaca que solicitou ao CFESS a "mala-direta" dos Conselhos para que a ocorrência da I Assembleia Sindical Pró-federação fosse informada ao conjunto dos assistentes sociais. Não podemos negar que os meios de comunicação se diversificaram, e outras formas de divulgação e propaganda se configuraram com o processo de globalização e mundialização do capital. Entretanto, há de se concordar que os espaços on-line não são suficientes ao movimento sindical construído para e pela base e que somente essas vias, igualmente, não são razoáveis para fomentar o debate acerca da construção de uma entidade representativa em âmbito nacional.

Ademais, a convocação expressa por meio de um simples convite por e-mail não significa o debate com o conjunto da categoria. Ou seja, ainda que o CFESS tenha disponibilizado sua "mala-direta" e tenha sido, outrossim, convidado para a mesa de abertura, isso não representou um convite ao debate ${ }^{11}$, tampouco expressou acúmulo

11 De acordo com o CFESS (2001), o convite direcionou-se à sua participação na 


\section{temporolis}

aprofundado acerca da temática.

O próprio discurso que fundamentava a criação da FENAS, ao afirmar que não havia tolerância para o debate acerca das questões sindicais por parte do conjunto CFESS/CRESS, desfez-se quando o Conselho (2001), em seu texto: "A contribuição do CFESS para o debate sindical", relata que a discussão aconteceu pouco tempo antes da criação da FENAS e que, nela, a categoria não orientou o retorno dos seus sindicatos, tampouco sua reinserção nesses espaços.

Naquilo que diz respeito às práticas burocráticas, desde a sua formação, podemos observar a consolidação de uma burocracia sindical - ou de um sindicalismo profissional - encastelada na direção da Federação, que se expressa, em particular, pela manutenção dos mesmos quadros sindicais na direção desde a sua fundação. Como exemplo desta afirmativa, destacamos a dirigente sindical Margareth Dallaruvera, que foi presidenta da FENAS de 2000 a 2012, e nos dias atuais integra a diretoria do Sindicato dos Assistentes Sociais do Rio de Janeiro (SASERJ). ${ }^{12}$

De acordo com o Estatuto da FENAS, sua direção é eleita a cada três anos no Congresso Nacional Sindical, que pode ser convocado extraordinariamente. Todavia, o Estatuto é omisso com relação ao interstício de mandato sindical.

Por fim, mas não menos importante, é possível identificar momentos em que a FENAS se recusou a encampar a luta dos assistentes sociais e do conjunto dos trabalhadores. Como exemplo dessa afirmação, considerada uma bandeira histórica do conjunto dos trabalhadores, houve a luta pela redução da carga horária de trabalho para assistentes sociais, vitoriosa no ano de $2010^{13}$ e protagonizada pelo conjunto CFESS/CRESS. Nessa batalha, a FENAS posicionou-se contrária à aprovação do PLC 152/2008 no dia em que seria votado. A justificativa

mesa de abertura e não à sua contribuição no debate. Esse foi o motivo pelo qual seus representantes não participaram da assembleia de fundação da FENAS.

12 Mandato de 2016 a 2019.

13 A Lei $n^{\circ} 12.317 / 2010$ trata da carga horária de trabalho do assistente social, que deve ser de 30 horas semanais, sem redução salarial. Apesar da sua aprovação, sua aplicação não foi respeitada pelos empregadores. Diante dessa conjuntura, o conjunto CFESS/CRESS convocou o Dia Nacional de Luta (30/8/2011), com a campanha "Lei Federal é pra Cumprir!". Foram realizados atos públicos em âmbito nacional para que a questão fosse evidenciada ao conjunto da sociedade. 


\section{temporollis}

para tal postura da Federação embasou-se na relativa preocupação com "[...] os $10 \%$ de assistentes sociais que conquistaram jornada inferior a 30 horas em acordos coletivos de trabalho em alguns municípios e estados." 14

Tal argumento não se sustenta, na medida em que o CFESS já havia realizado essa discussão com os Conselhos Regionais e com a categoria, assegurando que a aprovação do projeto de lei não traria prejuízos a esses profissionais, pois essas conquistas são expressas em legislações municipais e estaduais. A postura da FENAS contribuiu para que a aprovação do projeto de lei fosse atrasada em um ano. Isso foi um verdadeiro ataque ao conjunto da categoria de assistentes sociais.

Outro aspecto importante para a análise e caracterização da FENAS está relacionado às suas "atividades sindicais". Seus materiais de divulgação sobre o balanço das atividades enaltecem sua participação nas instâncias e fóruns do governo.

Desde a sua criação a diretoria da FENAS sempre esteve presente nos debates para os quais foi convidada. Filiou-se à CUT no dia da sua criação [...]; assumiu a mesa de negociação do SUS, participando também dos grupos de trabalho referentes à jornada de trabalho do SUS, comunicação e implantação das mesas municipais e estaduais em todo Brasil; conquistou titularidade no Conselho Nacional de Assistência Social - CNAS no segmento dos trabalhadores e suplência no Conselho Nacional de Saúde. (ALVARENGA; DALLARUVERA, 2007, p. 196).

A participação em espaços que discutem as políticas sociais que instrumentalizam a prática da grande maioria dos assistentes sociais no Brasil possui limitações. A proposta de participação nos conselhos pode contribuir para um rebaixamento da inserção dos movimentos sociais, dos usuários dos serviços e dos trabalhadores organizados na luta do conjunto da classe trabalhadora e, além disso, a política aprovada nesses espaços pode pôr-se de acordo com os interesses dos diferentes governos e do capital ou, ainda quando em desacordo, não ser respeitada.

Considerando as limitações dos espaços de conciliação de classes, destacamos que a participação da FENAS nos conselhos e fóruns

14 O CFESS defendeu aprovação imediata do PLC 30 h. 


\section{tempordis}

deveria ter sido deliberada pelo conjunto da categoria. Os assistentes sociais deveriam ter tido a oportunidade de discutir com a "sua" Federação se esta iria ou não representá-los nos espaços governamentais, e em quais deles seria estratégica a participação. Isso nos mostra que o balanço sindical de uma entidade não pode ser pautado pela sua participação em atividades que nem sequer foram discutidas e aprovadas coletivamente.

A FENAS hoje passa por um processo de expansão quantitativa, com 14 sindicatos de diversos estados filiados e talvez alguns outros que contam com seu apoio para as suas respectivas reaberturas. Porém, a análise cuidadosa da sua prática sindical evidencia que essa Federação foi gestada a partir de uma avaliação reducionista e precipitada, pautada nos marcos da crise do sindicalismo no Brasil e aliada à tentativa de recuperação do sindicalismo cutista, considerando-se o aprofundamento da sua crise de legitimidade. A (re)abertura de novas entidades filiadas à CUT proporcionaria o aumento do número de sindicatos na sua base, bem como do quantitativo de verbas repassadas para a sua existência e manutenção. ${ }^{15}$

Por fim, entendemos que a polêmica que tange à melhor forma de organização sindical, neste momento, não é a principal divergência para se contextualizar os limites e entraves da organização político-sindical dos assistentes sociais, visto que a própria caracterização da Federação Nacional se mostra como o maior obstáculo para uma reorganização da categoria que esteja aliada ao conjunto da classe trabalhadora e, nesse sentido, a sua existência reafirma a transição inconclusa na atualidade.

\section{Considerações Finais}

A organização político-sindical dos assistentes sociais na atualidade remonta ao amplo debate acerca da melhor estrutura sindical que organize os trabalhadores contra os ataques do governo. A polêmica concernente às entidades corporativas ou por ramo de atividade

15 Não podemos afirmar se, para as demais categorias profissionais, houve a retomada dos sindicatos corporativos e, tampouco, se ocorreu no mesmo período de degradação e crise daquilo que, um dia, foi a maior expressão da organização sindical dos trabalhadores no Brasil - a CUT. Entretanto, com relação ao Serviço Social, essas associações não podem ser deixadas em segundo plano. 


\section{temporolis}

representa a reflexão sobre a melhor forma de organização dos trabalhadores que lhes permita o enfrentamento com o capitalismo em seu atual estágio de desenvolvimento.

$\mathrm{Na}$ atualidade, passamos por um período de mundialização do capital, no qual estratégias econômicas, políticas e sociais, por parte do capital e seus representantes, contribuem para a atomização do trabalhador e o enfraquecimento da luta conjunta. Se, por um lado, o capitalismo torna-se cada vez mais orgânico, por outro, os trabaIhadores, a partir da reestruturação produtiva, ficam cada vez mais isolados, dispersos e pulverizados.

Embora os sindicatos por ramo não nos pareçam ser um princípio político, tampouco uma prerrogativa imutável, na atual conjuntura de fragilidade do movimento - em virtude das novas configurações do capitalismo -, torna-se urgente o fomento de entidades organizativas da classe trabalhadora que proponham a unificação dos seus diversos setores - divididos pelo próprio capital.

Infelizmente, as entidades sindicais dos assistentes sociais que foram reabertas são resultado de uma política de conciliação de classes nada combativa e reafirmam, ainda, a transição inconclusa da organização político-sindical dos assistentes sociais. No entanto, não há como negar a sua existência e seu papel social nesse contexto. Os sindicatos dos assistentes sociais reabertos foram conformados pelas orientações cutistas pelegas, o que difere, em muito, do enfrentamento das condições que levam o trabalhador ao isolamento. Não podemos esperar que as direções atuais sejam combativas, dadas as suas direções políticas, mas acreditamos que cabe ao conjunto da categoria decidir, coletivamente, os rumos desse impasse.

\section{REFERÊNCIAS}

ABRAMIDES, Maria Beatriz Costa A organização político-sindical dos assistentes sociais: trajetória de lutas e desafios contemporâneos. Serviço Social \& Sociedade. São Paulo, n. 97, v. 30, p. 85-108, jan./mar. 2009.

; CABRAL, Maria do Socorro Reis. O novo sindicalismo e o serviço social: trajetória e processos de luta de uma categoria - 19781988. São Paulo: Cortez, 1995. 
$\therefore$ . O significado do papel político do III Congresso Brasileiro de Assistentes Sociais - CBAS - 1979. Serviço Social \& Sociedade, São Paulo, n. 100, v. 30, p. 728-39, out./dez. 2009 a.

. A organização política do serviço social e o papel da CENEAS/ ANAS na virada do serviço social brasileiro. CFESS. Conselho Federal de Serviço Social (Org.). 30 Anos do Congresso da Virada, Brasília-DF, 200gb.

ALVARENGA, Mariza Pereira; DALLARUVERA, Margareth Alves. Por que Fenas? A história contada por seus protagonistas. Serviço Social \& Sociedade, São Paulo, v. 28, n. 92, p. 187-200, nov. 2007.

ANTUNES, Ricardo. O novo sindicalismo no Brasil. São Paulo: Pontes, 1995.

BRASIL. Decreto-Lei n, 5.452, de 1 de maio de 1943. Aprova a Consolidação das Leis do Trabalho. Diário Oficial da União, Poder Executivo, Brasília-DF: 9 ago. 1943. Disponível em: <http://www.planalto.gov.br/ ccivil_03/decreto-lei/Del5452.htm>. Acesso em: 7 jan. 2012.

CUT. Central Única dos Trabalhadores. Resoluções do 2 Congresso Nacional da CUT: $2^{\circ}$ Concut). 1986 . Rio de Janeiro: CUT, 1986. Disponível em: <https://www.cut.org.br/system/uploads/document/490ed55booaoa6b5eea9aa486ae719f3/file/2-congresso-nacional-da-cut2-concut-31-07-a-03-08-1986.pdf>. Acesso em: 8 fev. 2012.

. Resoluções do 4 Congresso Nacional da CUT ( $4^{\circ}$ Concut). São Paulo: CUT, 1991. Disponível em: < https://www.cut.org.br/system/ uploads/document/4a876924ac432c9b70b6ce7b965472fa/file/4-congresso-nacional-da-cut-4-concut-04-a-08-09-1991.pdf>. Acesso em: 8 fev. 2012.

. Resoluções do 7 Congresso Nacional da CUT ( $7^{\circ}$ Concut). 2000. Serra Negra: CUT, 2000. Disponível em: < https://www.cut.org. br/system/uploads/document/b914a5d169c187f5c3b4dd5124cbf29f/fi- 


\section{temporollis}

le/7-congresso-nacional-da-cut-7-concut-15-a-19-08-2000.pdf>. Acesso em: 8 fev. 2012.

. Resoluções da 10 Plenária Nacional da CUT. São Paulo: CUT, 2002. Disponível em: <https://www.cut.org.br/system/uploads/document/b38c9385b22b0197c4ced31802c7e349/file/10-plenaria-nacionalda-cut-08-a-11-05-2002.pdf>. Acesso em: 8 fev. 2012.

CFESS. Conselho Federal de Serviço Social. A contribuição do CFESS para o debate sindical. Rio de Janeiro: CFESS, 2001. (Texto mimeo).

FENAS. Federação Nacional dos Assistentes Sociais. Resgate histórico da organização política da categoria. Informativo FENAS, Rio de Janeiro, Ed. esp. jul. 2010. Disponível em: <http://www.sasers.com.br/ arquivos/fenas-uerj.pdf $>$ Acesso em: 10 nov. 2011.

. Estatuto da Federação Nacional dos Assistentes Sociais. Rio de Janeiro, jan. 2011. Disponível em: <http://www.fenas.org.br/materias.html> Acesso em: 12 fev. 2012.

HORTA, Danielle Silva da. A trajetória histórica da organização político-sindical dos assistentes sociais no estado do Rio de Janeiro. 2009. 302 f. Dissertação (Mestrado em Serviço Social)- Universidade Federal do Rio de Janeiro, Rio de Janeiro, 2009.

PAULO NETTO, José. III CBAS: algumas referências para sua contextualização. In: CFESS. Conselho Federal de Serviço Social (Org.). 30 Anos do Congresso da Virada, Brasília-DF, 2009. 